PATRICIO BASCUÑÁN CORREA

ESCUELA DE DISEÑO

FACULTAD DE ARQUITECTURA, ARTE Y DISEÑO

UNIVERSIDAD DIEGO PORTALES

SANTIAGO, CHILE

PATOBASCUNAN@HOTMAIL.COM
Fecha de recepción: 29/01/2015

Fecha de aceptación: 12/04/2016

Cómo citar: Bascuñán Correa, P. (2016). La

tipografía moderna entre la ideología y la utilidad.

Una revisión de las propuestas de Jan Tschichold y

Otl Aicher. RChD: creación y pensamiento, I(1), 95-103.

DOI: 10.5354/0718-2430.2016.44315

\section{La tipografía moderna entre la ideología y la utilidad. Una revisión de las propuestas de Jan Tschichold y Otl Aicher}

\author{
Modern Typography: Between Ideology and Utility. A Revision \\ on the Proposals From Jan Tschichold and Otl Aicher
}

Resumen. Este texto busca generar una reflexión crítica en torno a los planteamientos de Jan Tschichold en La nueva tipografía (1928), un hito que marcó una fractura en el desarrollo de la tipografía, en la misma línea de las vanguardias, al contrastarlos con los conceptos sobre tipografía que desarrolla Otl Aicher, fundador de la HfG-Ulm, en su libro Tipografía (2004). Y es que, a pesar de que ambos autores aboguen por un ejercicio del diseño gráfico basado en la legibilidad y el concepto de orden, proponiendo un diseño abierto y democrático, existen puntos en donde discrepan, como es el rechazo de la tradición de la escritura romana por parte de Tschichold y su tendencia a anteponer la ideología a la utilidad, en donde Aicher responde desde su pragmatismo. Así, al visibilizar aquellas discrepancias se pretende desmitificar la denominada tipografía funcionalista impulsada por Tschichold, reconociendo sus errores y aciertos, en pos de una tipografía basada en un principio de utilidad que sepa rescatar lo mejor de lo nuevo y la tradición.

Palabras clave: HfG-Ulm, modernidad, tipografía.

\begin{abstract}
This paper seeks to generate a critical reflection on the ideas of Jan Tschichold in The New Typography (1928), a milestone that marked a break in the development of typography, in the same line of the avant-garde, to contrast them with the typography concepts developed by Otl Aicher, founder of the HfG-Ulm, in his book Typography (2004). Even both authors advocate an exercise of graphic design based on legibility and the concept of order proposing an open and democratic design, there are aspects where they disagree, as the rejection of the Roman writing tradition made by Tschichold and its tendency to precede the ideology to the utility, where Aicher answers from his pragmatism. In this way, after making visible those discrepancies it is intended to demystify the so-called functionalist typeface driven by Tschichold, acknowledging their mistakes and successes, in pursuit of a type-face design based on a principle of utility that aims to rescue best of the new and tradition. Keywords: HfG-Ulm, modernity, typography.
\end{abstract}

Revista Chilena de Diseño,

RChD: creación y pensamiento

Universidad de Chile

2016, 1(1)

http://rchd.uchile.cl 


\section{Introducción}

Desde la invención de la imprenta no hubo una ruptura en el diseño tipográfico tal como la que supuso en 1928 la publicación Die Neue Typographie (La nueva tipografía), escrita por el tipógrafo alemán Jan Tschichold (2003). En un contexto donde prevalecía el esteticismo y una ecléctica revisión de modelos históricos, La nueva tipografía abrió una senda para un diseño basado en la funcionalidad, desechando los elementos ajados de la tradición y consolidándose como un reflejo auténtico de una época caracterizada por las vanguardias, la transformación social y el recambio tecnológico.

Tras casi un siglo de su aparición, son muchas las lecturas que podemos realizar de La nueva tipografía. Sucede que es innegable la trascendencia de su aporte al considerar que muchos de sus planteamientos siguen vigentes hasta nuestros días. La eliminación de la ornamentación, la estandarización de formatos y la inclusión de la fotografía son algunas de las innovaciones por las cuales Tschichold luchó y logró instalar en el campo del diseño editorial, cosa que hoy más vale agradecer. Sin embargo, su obstinación por borrar todo ápice de tradición, barriendo con siglos de progresos lentamente fraguados (cosa de lo que, tal como revisaremos más adelante, el mismo Tschichold se arrepentiría), han hecho que en la actualidad muchos de sus postulados hayan sido desechados y que se haya tenido que recurrir a referentes clásicos para dar continuidad al desarrollo de la tipografía.

Dentro de la línea de aquellos que han sabido encontrar en la tradición referencias para innovar en el campo del diseño tipográfico, nos encontramos con otro alemán, el tipógrafo, diseñador y educador Otl Aicher. Desde otro contexto distinto al de Tschichold, tras su paso como directivo de la HfG-Ulm y luego de una fructífera carrera como diseñador, Aicher publica Tipografía (2004), un conjunto de planteamientos acerca de lo que debe ser un diseño gráfico democrático e inclusivo, en donde la tipografía cumple un rol fundamental. En este libro es posible entrever que, aunque al igual que Tschichold el autor niegue tajantemente el esteticismo, sus planteamientos difieren principalmente en dos cosas: por un lado, Aicher reconoce que en la tradición, específicamente en la escritura romana, existen insumos para un diseño contemporáneo y funcional; por otro lado, frente a la tendencia de Tschichold de anteponer la ideología a la utilidad al entender lo "moderno" como un valor en sí, Aicher responde con un convencido pragmatismo.

En el presente artículo se buscará generar una reflexión crítica en torno a los planteamientos de Jan Tschichold en La nueva tipografía al evidenciar su sesgo ideológico y al contrastarlos con los conceptos sobre tipografía que desarrolla Otl Aicher en Tipografía. El énfasis estará en aquellos puntos en donde discrepan los autores, precisamente en los que ya se han mencionado, como es el rechazo de la tradición de la escritura romana por parte de Tschichold. Así, al visibilizar aquellas discrepancias se pretende desmitificar la denominada tipografía funcionalista impulsada por Tschichold, reconociendo sus errores y aciertos, en pos de una tipografía basada en un principio de utilidad que sepa rescatar lo mejor de la tradición. 
La nueva tipografía: manual para diseñadores modernos

El joven Tschichold, con tan solo 26 años, sentenciaba en 1928:

Los instrumentos de la generación actualmente dominante adolecen del fatal compromiso entre un supuesto propósito "artístico" y las necesidades y ataduras tecnológicas, de un servil retorno al pasado en pos de paralelismos históricos, así como del conflicto de esencia y apariencia. En vez de aceptar plasmar las regularidades de la producción mecánica, se contentaron con ser el medroso epigonismo de una “tradición” por lo demás ilusoria.(Tschichold, 2003, p.11)

El trabajo de Tschichold, tanto de tipógrafo como teórico, se enmarca en un contexto de posguerra caracterizado por una decadencia general en el mundo de la tipografía que venía arrastrándose desde el siglo XIX. Tal como se puede entrever en las palabras del tipógrafo, por más que existía un gran desarrollo en lo que respecta a la mecanización y las técnicas industriales por un amplio sector involucrado en el rubro de la impresión, existía una negación a asimilar las nuevas posibilidades que ofrecía la tecnología. Predominaba una imitación totalmente superficial y ecléctica de todo estilo anterior, aquel "medroso epigonismo" que menciona Tschichold, además de una completa arbitrariedad en el diseño estético (Figura 1).

Las respuestas frente a dicho panorama ya se avizoraban a finales del siglo XIX con el surgimiento de dos actitudes, diametralmente opuestas entre sí, que buscaban enfrentarse a la decadencia generalizada en las artes gráficas: el Jugendstil, que buscaba incorporar novedades derivadas de la Revolución Industrial , y el Nuevo Clasicismo, que desde una postura conservadora buscó un retorno a la tradición. Sin embargo, a pesar de las diferencias, el cambio tiene un denominador común y es el surgimiento del Buchkunst, el arte del libro.

El Buchkunst suplantaría al buchdruckerkunst, el arte de imprenta, instalando una nueva consideración del arte frente a lo que era una mera consideración técnica. Surgiría así un nuevo profesional proveniente del exterior de la imprenta, el buchkünstler, el artista del libro, quien además de dedicarse a la ilustración, la caligrafía y la creación de tipos, asumiría el diseño del libro y libro controlaría cada paso de su producción, esto con el fin de obtener una obra concebida unitariamente. Esto es de suma importancia si se tiene en cuenta que, tal como propone Kinross (1992), ${ }^{1}$ la tipografía moderna llega

cuando el arte de la imprenta, entendido como el conjunto todavía inarticulado de prácticas a partir de unos materiales de producción, se convierte en diseño tipográfico, es decir, en la configuración consciente del producto obtenido a través de la instrucción. (Kinross, 1992, p.9)

Influenciado tanto por el Jugendstil como por las corrientes funcionalistas de la época, el nuevo arte del libro, por el hecho de concebir el diseño de cada elemento como parte de un conjunto, evitando así que el resultado dependiera estrictamente de las pericias técnicas de cada operario, permitiría la consecución de la unidad estética y funcional de la obra. La belleza ya no estaría dada por la ornamentación ni la imitación de corrientes artísticas

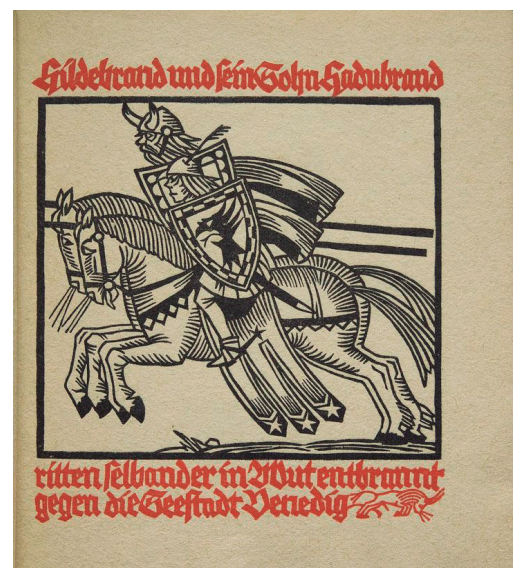

Figura 1. Portada de Das Hildebrandlied de Wilhelm Gerstung. Este diseño realizado en 1926 por Rudolph Koch, profundo admirador de la obra de William Morris y uno de los más destacados exponentes de la gráfica del Jugendstil, da cuenta de cómo los postulados de Jan Tschichold coexistieron con visiones conservadoras, ancladas en el historicismo y el trabajo artesanal, que no hacían eco de del desarrollo del arte de vanguardia ni de los desarrollos técnicos de la industria imprentera.

1. Citado en Pujol (2003). 


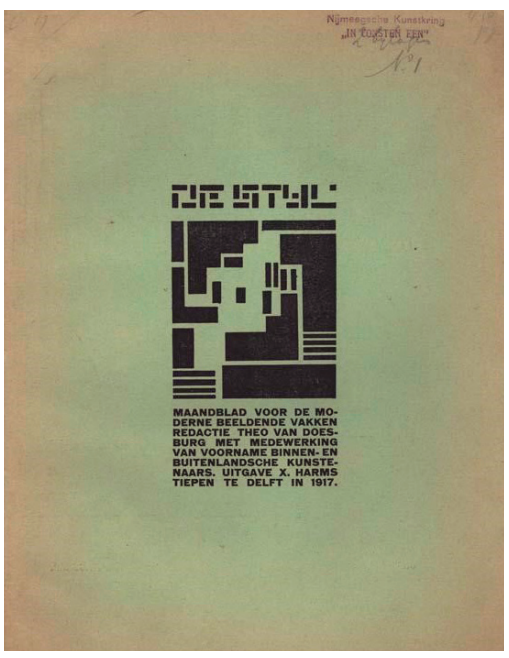

Figura 2. Portada de revista De Stijl (no.1, 1917), el principal órgano de difusión del movimiento artístico que llevaba el mismo nombre que contó con la participación de artistas como Piet Mondrian y Theo Van Doesburg. Aquí es posible apreciar como, desde el seno de las vanguardias y de forma previa a los postulados de Tschichold, la abstracción geométrica comulgaba con la tipografía de palo seco en lo que sería la representación de una "cosmovisión moderna". Fuente: <http://www.ubu.com/>

2. Para adentrarse en el debate y conflicto entre la cultura burguesa alemana del siglo diecinueve, imbuida de elementos románticos e idealistas, frente a las nuevas exigencias de la tipificación y racionalización emergente de los sectores intelectuales ligados a la producción industrial, véase Maldonado (1979). efectuadas sin dirección, sino que se encontraría en su funcionalidad, es decir, en la comunicación escrita del pensamiento. De este modo la tipografía adquiriría un rol fundamental, tanto en la estructuración interna como en la apariencia del libro, suprimiendo paulatinamente el uso de ornamentos.

Tschichold, influenciado fuertemente por las vanguardias, con las cuales tendría contacto directo, sobre todo por el constructivismo y el suprematismo, profundizaría el camino que abriría en la gráfica el Jugendstil y las corrientes funcionalistas de su época. Al igual que muchos otros artistas, arquitectos y diseñadores de su generación, que se formarían en sintonía con los nuevos avances tecnológicos, recibiría la influencia directa de aquellas nuevas propuestas que buscaban ligar el arte y las técnicas industriales, anteponiendo la razón y funcionalidad frente a esa añeja visión romántica e idealista de una "belleza absoluta" que predominaba en la época. ${ }^{2}$

Los objetivos de Tschichold fueron claros: imponer una nueva tipografía cuya esencia fuese la claridad y erradicar la antigua tipografía la cual, según él, basaba su diseño en fines estéticos, consiguiendo de esa manera dar forma un diseño tipográfico que reflejara el espíritu de la época, dejando de una vez por toda la nostalgia de lado y la constante reminiscencia de un pasado. Su justificación: la necesidad de una economía de expresión en la tipografía, por medio de un diseño austero y funcional, pensando en hacer accesible y democrático el acceso a la información en un época donde la saturación de material impreso era ya un problema.

En 1925 Tschichold publica Elementare Typographie (Tipografía elemental), un breve manifiesto del cual La nueva tipografía sería la profundización en detalle de los planteamientos ahí expuestos. Ya con el concepto "elemental" en el título y la primera frase del manifiesto (" 1 . La nueva tipografía se subordina a su finalidad") se puede entrever el anhelo de dar con una "forma pura", algo propio de aquella época, en donde, desde el seno de las vanguardias, los valores históricos no tendrían cabida, menos aún la ornamentación y lo superfluo. A pesar de que Tschichold no sería el creador de la nueva tipografía, y que esta ya se practicaba por personajes ligados a la Bauhaus (como Herbert Bayer) y las vanguardias (Figura 2), el tipógrafo alemán sería el primero en darle forma a través de un cuerpo teórico, aunando de esa manera sus manifestaciones aisladas y sentando las bases de lo que sería su desarrollo.

Las principales propuestas de La nueva tipografía fueron:

1. la valoración de un diseño tipográfico funcional, en donde la forma externa esté basada a partir de las funciones del texto, apelando a la legibilidad y a la coherencia entre las partes;

2. la negación de la ornamentación, incluso geométrica;

3. el fin de la atadura a los modelos históricos;

4. Ios principios de un diseño asimétrico, basado en una expresión rítmica, en donde el texto pudiese desplegarse de modo más dinámico, sustituyendo así la inamovilidad y monumentalidad del texto compuesto con un eje central simétrico;

5. la consideración del "blanco" o del espacio como elemento fundamental para composición;

6. la búsqueda por una normalización de los formatos de papel, basado en las normas alemanas establecidas por DIN (Deutsches Institut für Normung), 
en pos de una racionalización del uso del papel;

7. la inclusión de la fotografía en el diseño tipográfico, reconocida como un medio objetivo de transmisión de información;

8. una alta valoración por las tipografías de palo seco, entendiendo los remates como un tipo de ornamentación.

Sin lugar a dudas el diseño gráfico de hoy no sería el mismo sin el aporte de La nueva tipografía. No obstante, a pesar del valor histórico que se le puede atribuir a los esfuerzos del tipógrafo alemán de impulsar una revolución tipográfica de sus elementos obsoletos, introduciendo nuevas técnicas como la fotografía, la estandarización y un nuevo dinamismo en la composición, es bastante cuestionable el hecho de desechar por completo la tradición, más aún si, tal como veremos más adelante, ello se debe a factores ideológicos, inclusive dogmáticos, que no se condicen con un aumento del valor de uso del diseño tipográfico.

\section{La guerra tipográfica}

El joven Tschichold al momento de escribir La nueva tipografía era un férreo enemigo del historicismo. Por lo mismo, al igual que muchos de sus contemporáneos ligados a los movimientos de vanguardia, sobre todo aquellos que abogaban por un arte abstracto, se sintió identificado con las formas geométricas puras, las cuales por un lado representaban una idea de universalidad al carecer de referencias históricas. Además la geometría era signo de todo un movimiento social que reconocía en la producción industrial, en donde se utilizaba prácticamente tan solo formas geométricas básicas, un motor de cambio y transformación social. Esto llegó a tal nivel que

el cuadrado, el círculo y el triángulo se tornaron en los símbolos de una nueva era, de una nueva cultura, de un alejamiento total de los valores históricos. [...] Entonces los elementos fundamentales del ser y del mundo vinieron a simbolizar la producción tecnológica, la sociedad industrial, la solidaridad proletaria y el internacionalismo. Se convirtieron en antorchas estéticas del rechazo por lo superfluo e irrelevante. (Aicher, 2004, p.181)

Esto claramente tuvo sus repercusiones en el mundo de la tipografía. Y es que a pesar de que en el siglo XIX ya existían los tipos de palo seco, carentes de ornamento y referencia histórica, no se declaró la "guerra tipográfica" hasta que la tipografía se elevó a doctrina cultural, a ideología relacionada con el nacimiento del arte abstracto. En este conflicto, que dejaría mucha tinta derramada, se enfrentarían los defensores de la tradición, quienes harían de la herencia de la escritura romana su estandarte, optando por el uso de tipos como Garamond, Bodoni, Didot y Caslon, contra quienes apoyaban a las vanguardias, la industria y la tecnología, quienes izarían las tipografías de palo seco, dibujadas con regla y compás, como sus banderas de lucha (Aicher, 2004, p.181).

Sin embargo, más allá del afán democrático y todo discurso sobre la universalidad, la idea de que una tipografía de palo seco, por el puro hecho de ser construida a base de una geometría carente de referencias a un trazo manual, garantiza una mejor legibilidad que la romana es completamente cuestionable. Y es que, tal como reconoció el mismo Tschichold tras toda su experimentación -y como posteriormente lo entendería Otl Aicher- se percató que la

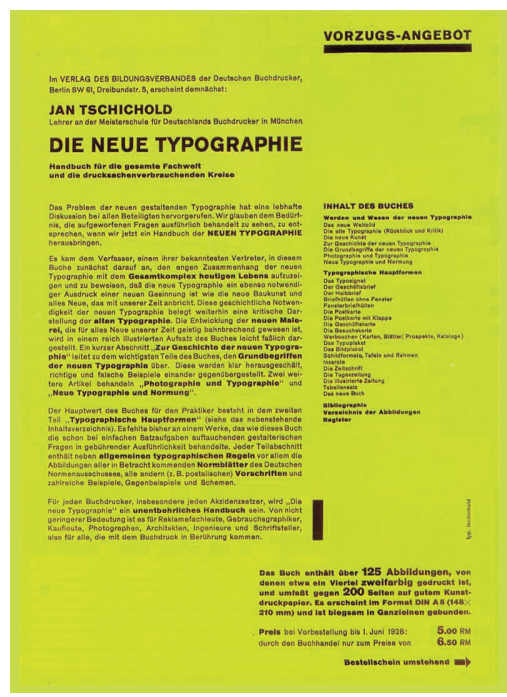

Figura 3. Folleto original de La nueva tipografía diseñado por Tschichold en 1928. Es destacable el empleo de una composición asimétrica, el uso de "blancos" y la total ausencia de ornamentación. Fuente: <http://www.catedracosgaya.com.ar/ tipoblog/2013/la-nueva-tipografia-jan-tschichold/s. 


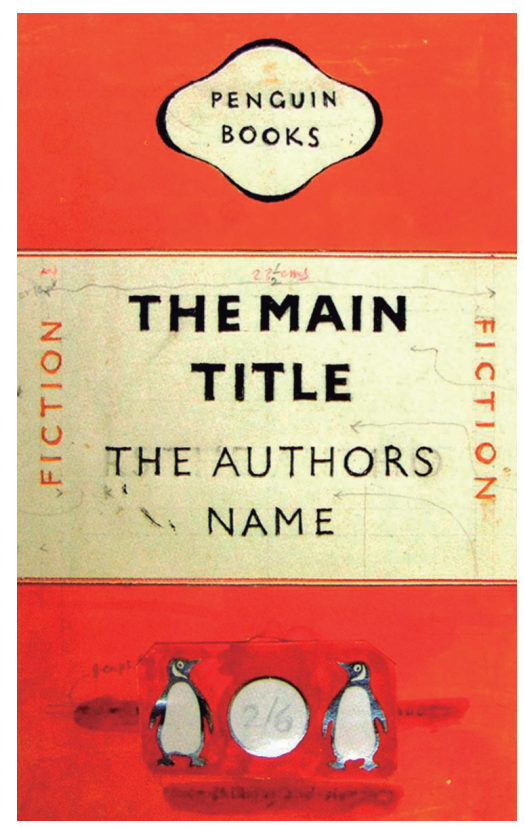

Figura 4. Maqueta con reglas de composición para portadas de la editorial Penguin realizada por Tschichold en 1935. Aquí es evidente el "regreso" del tipógrafo alemán hacia una axial. Cabe mencionar que, pasada la euforia de las vanguardias y la juventud, los trabajos de un Tschichold más maduro contradicen casi todos sus postulados de La Nueva Tipografía, Ilegando incluso a diseñar una tipografía basada en Garamond llamada Sabon.

Fuente: <http://www.designishistory.com/1920/ jan-tschichold/>.

tipografía de palo seco, a pesar de que funcionaba muy bien en afiches publicitarios o pequeños impresos, su uso no era apropiado para libros o textos de gran extensión. Su utilización se debía simplemente a razones ideológicas, no utilitarias. Entre medio de una controversia que sostendría con Max Bill, el primer director de la HfG-Ulm, Jan Tschichold escribiría en 1946:

El cumplimiento de reglas que han tardado siglos en fraguarse es tan poco "historizante" y ecléctico como la utilización por un constructor de máquinas de patentes de otros ingenieros. Por el contrario, es un signo de inmadurez el arrojar por la borda y con desdén las reglas antiguas y proscribirlas a cualquier precio e intentar nuevas vías, por el mero hecho de ser diferente y "moderno". (Tschichold, 2003, p.266)

No debiera sorprender el "regreso" de Tschichold hacia al clasicismo luego de su entusiasta propuesta juvenil (Figura 4) Sin embargo, llama la atención que poco o nada de sus planteamientos estuviesen latentes en las últimas propuestas que desarrolló, tales como el sistema de composición que diseñaría para Penguin Books en 1947 o el diseño de la tipografía Sabon, un tipo basado en el trabajo de Claude Garamond, que realizaría entre 1964-1967, que prácticamente vendrían a contradecir todo lo expuesto por él en La nueva tipografía. Tschichold se asumiría como perdedor de la guerra que lideraría y se cambiaría de bando sin siquiera buscar concesiones.

Tendría que pasar un tiempo para que los postulados "modernos" de Tschichold dejaran de ser novedad y fueran revisados críticamente desde la distancia. Así, ciertos elementos de la tradición volverían a tener vigencia en un diseño moderno que no estaría cegado por el esplendor de las vanguardias.

\section{Hacia la comunión del palo seco y la romana}

Otl Aicher en su libro Tipografía (2004), en la revisión que hace de la historia de la escritura de occidente, es enfático en decir que los tipos de escritura construidos tan solo a partir de una geometría abstracta jamás han servido para la escritura, siendo estos empleados tan solo útiles con fines estéticos y políticos, como por ejemplo para resaltar la monumentalidad de las instituciones. Por lo mismo, Aicher se esmera en dar cuenta de que en Europa ha habido el desarrollo de dos escrituras en paralelo: una para escribir y otra para el énfasis ostentoso (Aicher, 2004).

Con respecto a los tipos de escritura empleados para la ostentación, el origen se remonta a la antigua Grecia, en donde, debido a la fuerte influencia de la geometría y del orden en el pensamiento griego, la uncial griega, un tipo de escritura proveniente de un trazo manual provisto de todas las irregularidades que aquello implica, fue sometida a un corsé geométrico, siendo sus formas subordinadas a un código formal basado en un cuadrado que encerraba un círculo y un triángulo. El resultado: un tipo de escritura modélico que derivaba de un principio de diseño único y que resaltaba por su claridad estética y homogeneidad (nada muy distinto, tanto en forma como en su lógica constructiva, a la Futura de Paul Renner de 1927). 
Dentro de la senda de la escritura que se ha desarrollado a partir de la construcción con modelos geométricos, apostando por estructuras estáticas y la homogeneidad de sus caracteres, nos encontramos expresiones, bastante distantes en el tiempo, como la capital romana (siglos I-II d.c.), las didonas de Didoty Bodoni (finales del siglo XVIII y principios del XIX) y los tipos de palo seco como Akzidenz-Grotesk (1896) o Futura (1927), siendo estos últimos empleados y adulados por Tschichold. Puntualmente los tipos de palo seco mencionados, tan solo cumplían un fin ostentoso, quizás no de monumentalidad, pero sí de una idea de "funcionalidad" y "modernidad", bastantes deseables por entonces, opacando lo más importante para un tipo de lectura: su legibilidad. Nos encontramos con la misma lógica de anteponer lo universal a lo concreto, el modelo geométrico frente al uso cotidiano, tanto en la capital romana que adorna el templo como en el diseño tipográfico en el libro de La nueva tipografía, en donde tan solo se utiliza una poco efectiva tipografía de palo seco.

Con respecto a la escritura pensada para escribir, aquella de uso cotidiano, su origen nada tendría que ver con la geometría, sino más bien con el irregular trazo a mano alzada. Y es que la homogeneidad, por más que en apariencia pueda lucir más bella e incluso "funcional", es un problema para la legibilidad. Esto se debe a que la definición de los caracteres individuales se pierde dentro de la uniformidad, en la apariencia de conjunto. Sucede que la particularidad de cada carácter es lo que permite que leamos imágenes verbales, es decir, palabras antes que letras separadas. "Un orden excesivo conduce a una similitud desmesurada de forma que la letra individual se extingue en medio de la estructura individual" (Aicher, 2004, p.49). Por lo mismo frente a la monumentalidad y la "alta cultura", en donde se antepone la escritura de letras a la escritura de palabras, ha existido siempre otros tipos de letras de uso cotidiano, en donde la irregularidad de los caracteres (con una cuota necesaria de orden, por supuesto) ha jugado un rol fundamental.

Dentro de los tipos de letra de uso cotidiano, se encuentra toda una línea que proviene directamente de la escritura con pluma sobre pergamino, en la cual nos encontramos con la minúscula Carolingia (80o D.c.) y la minúscula humanista (siglo.xv), encontrándose uno de sus puntos más altos de desarrollo a mediados del siglo XVI con el trabajo de Claude Garamond. Por más "tradicional" e incluso "irracional" que pueda lucir la tipografía romana, ha demostrado con el tiempo ser de lo más efectiva y funcional.

No obstante $-y$ aquí nos volvemos a amistar con los planteamientos de Tschichold - a pesar de todas las virtudes de la escritura romana, es innegable de que puede existir y haya existido un latente historicismo en su uso, además de que es posible percibir los remates como un exceso en el dibujo de sus letras, hasta el punto de poder considerarlos como superfluos y ornamentales. En este sentido, si es que se mira desde una mirada esencialista, es ante todo preferible la tipografía de palo seco.

Entonces, ¿bajo qué criterio valorar el empleo de un tipo de escritura? Otl Aicher es categórico y responde: según su función.

\section{$\mathrm{R} R \underline{\mathrm{R}} \mathrm{R}$}

Figura 5. La familia tipográfica Rotis diseñada en 1988 por Otl Aicher viene a ser el fruto de todo un estudio y reflexión acerca de la legibilidad en la escritura. Recogiendo lo mejor de la tradición geométrica y del trazo humanista, Aicher propone, además de las variantes de peso e inclinación, las cuatro variantes de estilo que aquí se muestran.

Fuente: Composición realizada por el autor.

3. Para revisar los planteamientos de Aicher acerca de cómo comprender un ejercicio del diseño basado en el pragmatismo, es decir desde lo concreto y particular y no desde el ideal o lo universal, véase Aicher (1991). 
A diferencia de Tschichold y su concepción de funcionalidad, Aicher siempre supo mantener una actitud objetiva frente a la eterna batalla entre defensores y detractores del uso de letras de palo seco; no se permitió jamás empapar por el fervor de ninguna vanguardia. Desde un convencido pragmatismo, 3 basándose en el juicio de utilidad en donde evalúa cada cosa según su finalidad, anteponiendo lo concreto y particular a lo ideológico y universal, Aicher sabe rescatar, luego de toda una revisión crítica de la historia, lo mejor de cada alternativa para configurar su propia propuesta: la tipografía Rotis (1957), un mix entre una romana y una palo seco.

En la misma lógica de configurar un sistema tipográfico como lo hizo Adrian Frutiger con Univers (1954), Aicher desarrolla su propio sistema en donde ofrece, además de las variantes de peso e inclinación, cuatro variantes de estilo: romana, semirromana, semi palo seco y palo seco, siendo la semi palo seco el pilar principal de la familia, al reunir la imagen de una romana que prescinde de los remates. De esta manera la propuesta de Aicher busca ofrecer una familia tipográfica coherente entre sus partes, además de permitir la versatilidad para su uso según los requerimientos de cada proyecto particular (Figura 5).

De esta manera Aicher supo dar continuidad a los planteamientos de Tschichold al pulirlos de su sesgo ideológico, que al fin de cuentas repercutía en la tan anhelada funcionalidad. Así es como Aicher supo orientar el ejercicio de un diseño basado en un principio de utilidad que sepa rescatar lo mejor de lo nuevo y la tradición. 


\section{Bibliografía}

Aicher, O (1991). El mundo como proyecto. Gustavo Gili.

Aicher, O (2004). Tipografía. Valencia: Campgràfic.

Kinross, R. (1992). Modern Typography. Londres:

Hyphen Press.

Maldonado, T. (1979). Técnica y Cultura. Buenos Aires:

Editorial Infinito.

Pujol, J. (2003). Introducción. En J. Tschichold. La nueva tipografía. Valencia: Campgràfic.

Tschichold, J. (1925). Elementare Typographie. Typographische Mitteilungen, (10).

Tschichold, J. (1928). Die Neue Typographie. Berlín: Verlag des Bildungsverbandes der Deutschen Buchdrucker.

Tschichold, J. (2003). La nueva tipografía. Valencia:

Campgràfic. 